\title{
Effects of long-term bronchodilators in bronchiectasis patients with airflow limitation based on bronchodilator response at baseline
}

This article was published in the following Dove Press journal:

International Journal of COPD

7 November 2016

Number of times this article has been viewed

\author{
Ho Jung Jeongl,* \\ Hyun Lee ${ }^{1, *}$ \\ Keumhee C Carriere ${ }^{2,3}$ \\ Jung Hoon Kim' \\ Jin-Hyung Han' \\ Beomsu Shin' \\ Byeong-Ho Jeong' \\ Won-Jung Koh' \\ O Jung Kwon' \\ Hye Yun Park' \\ 'Division of Pulmonary and Critical \\ Care Medicine, Department of \\ Medicine, Samsung Medical Center, \\ Sungkyunkwan University of Medicine, \\ Seoul, South Korea; ${ }^{2}$ Department of \\ Mathematical and Statistical Sciences, \\ University of Alberta, Edmonton, $A B$, \\ Canada; ${ }^{3}$ Biostatistics and Clinical \\ Epidemiology Center, Samsung \\ Medical Center, Seoul, South Korea \\ *These authors contributed equally \\ to this work
}

Correspondence: Hye Yun Park Division of Pulmonary and Critical Care Medicine, Department of Medicine, Samsung Medical Center, Sungkyunkwan University School of Medicine, 8I Irwon-ro, Gangnam-gu, Seoul 0635I, South Korea

$\mathrm{Tel}+82234103429$

Fax +82 234103849

Email hyeyunpark@skku.edu
Purpose: The association between positive bronchodilator response (BDR) at baseline and the effect of long-term bronchodilator therapy has not been well elucidated in patients with bronchiectasis. The aims of our study were to explore the association between positive BDR at baseline and lung-function improvement following long-term (3-12 months) bronchodilator therapy in bronchiectasis patients with airflow limitation.

Materials and methods: The medical records of 166 patients with clinically stable bronchiectasis who underwent baseline pre- and postbronchodilator spirometry and repeated spirometry after 3-12 months of bronchodilator therapy were retrospectively reviewed. For analysis, patients were divided into two groups, responders and poor responders, based on achievement of at least $12 \%$ and $200 \mathrm{~mL}$ in forced expiratory volume in 1 second $\left(\mathrm{FEV}_{1}\right)$ following bronchodilator therapy from baseline $\mathrm{FEV}_{1}$.

Results: A total of 57 patients (34.3\%) were responders. These patients were more likely to have positive BDR at baseline than poor responders (38.6\% [22 of 57] vs $18.3 \%$ [20 of 109], $P=0.004)$. This association persisted after adjustment for other confounding factors (adjusted odds ratio 2.298, $P=0.034$ ). However, we found $\mathrm{FEV}$, improved significantly following longterm bronchodilator therapy, even in patients without positive BDR at baseline (change in $\mathrm{FEV}_{1}$ $130 \mathrm{~mL}$, interquartile range -10 to $250 \mathrm{~mL} ; P<0.001$ ).

Conclusion: Positive BDR at baseline was independently associated with responsiveness to long-term bronchodilator therapy in bronchiectasis patients with airflow limitation. However, $\mathrm{FEV}_{1}$ improvement was also evident in bronchiectasis patients without positive BDR at baseline, suggesting that these patients can benefit from long-term bronchodilator therapy.

Keywords: bronchodilator effect, bronchodilator agents, bronchiectasis, airway obstruction

\section{Introduction}

Bronchiectasis is a suppurative airway disease that has been defined as an abnormal and permanent bronchial dilatation. ${ }^{1}$ Although the exact pathogenesis of bronchiectasis is still not clear, it is believed to be due to the development of a vicious cycle of chronic inflammation and altered response to infection by compromised mucociliary clearance, leading to progressive airway destruction and distortion. ${ }^{2}$ Furthermore, airwaywall thickening, chronic colonization of Pseudomonas aeruginosa in the bronchial epithelium, excessive airway collapse during expiration, and bronchial hyperreactivity may contribute to deterioration of lung function in patients with bronchiectasis. ${ }^{3-6}$

One mainstay of bronchiectasis management is pharmacologic treatment. ${ }^{7,8}$ While there is accumulating evidence supporting the use of anti-inflammatory therapy (eg, inhaled corticosteroids $\mathrm{s}^{9,10}$ and macrolides ${ }^{11-13}$ ) and antibiotics, data supporting 
bronchodilator use in patients with bronchiectasis are scarce and recommendations based mainly on expert opinion. The British Thoracic Society guideline for noncystic fibrosis bronchiectasis suggests that bronchodilator use may be appropriate for patients with bronchiectasis who have reversible airflow limitation. ${ }^{7}$ However, data supporting this recommendation are from small-scale studies showing a significant reversibility of airflow limitation in response to short-acting bronchodilator use in patients with bronchiectasis. ${ }^{5,14}$ Moreover, short-term bronchodilator response is a poor predictor of long-term treatment benefit for lung function in chronic obstructive pulmonary disease (COPD). ${ }^{15}$ On the other hand, the long-term effect of bronchodilator therapy on lung function has not been adequately investigated in patients with bronchiectasis. ${ }^{16-18}$ Therefore, the aims of our study were to explore the relationship between reversible airflow limitation, ie, positive bronchodilator response (BDR) at baseline, and lung-function improvement after long-term (3-12 months) bronchodilator therapy in bronchiectasis patients with airflow limitation.

\section{Materials and methods}

\section{Patients}

The medical records of 206 patients aged 18 years or older at a university-based tertiary hospital were evaluated. All patients had bronchiectasis on chest computed tomography (CT) scan, and had performed pre- and postbronchodilator spirometry when they were clinically stable and repeated spirometry after 3-12 months of bronchodilator therapy between January 1995 and February 2015. Among these patients, we excluded those who had more than a 6-month interval between baseline spirometry and initiation of bronchodilator therapy $(n=34)$ and those without airflow limitation at baseline $(n=6)$. A final total of 166 patients with concomitant bronchiectasis and airflow limitation were included (Figure 1). The institutional review board of Samsung Medical Center approved this study and waived the requirement for informed consent due to the retrospective nature of the study.

\section{Pulmonary function test}

Spirometry was performed as recommended by the American Thoracic Society/European Respiratory Society using a Vmax 22 (SensorMedics, Yorba Linda, CA, USA). ${ }^{19}$ The highest measured forced vital capacity (FVC) and forced expiratory volume in 1 second $\left(\mathrm{FEV}_{1}\right)$ among three or more tests with acceptable curves were used. Absolute values of $\mathrm{FVC}$ and $\mathrm{FEV}_{1}$ were obtained, and the percentage

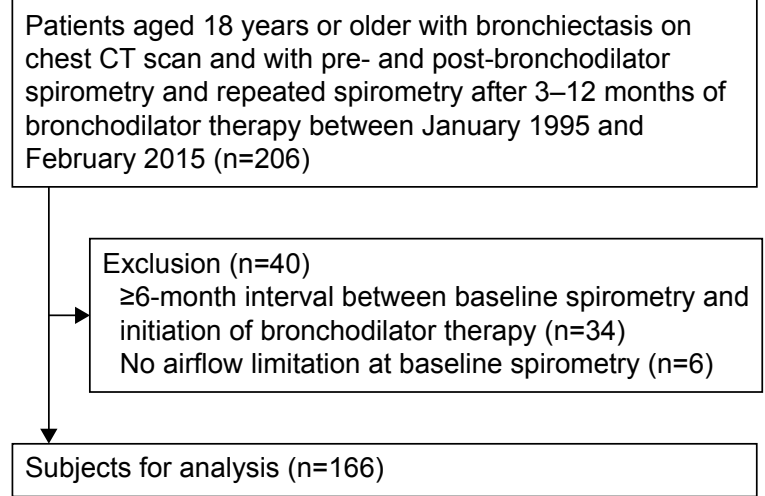

Figure I Study flowchart.

Abbreviation: CT, computed tomography.

of predicted values for $\mathrm{FEV}_{1}$ and $\mathrm{FVC}$ were calculated from equations obtained in a representative South Korean sample. ${ }^{20}$ Airflow limitation was defined as prebronchodilator $\mathrm{FEV}_{1} / \mathrm{FVC}<70 \%$. Positive BDR at baseline was defined as postbronchodilator increase in $\mathrm{FEV}_{1}$ and/or FVC of at least $12 \%$ and $200 \mathrm{~mL}$ from baseline values at 15 minutes after inhalation of $400 \mu \mathrm{g}$ of salbutamol. ${ }^{21}$

\section{Definitions}

Bronchiectasis was diagnosed when the following two key imaging findings were present on CT scan: 1) the internal diameter of the bronchus was larger than the accompanying vessels and 2) no bronchial tapering was present in the periphery of the lungs. ${ }^{22,23}$ All CT scans were reviewed by two pulmonologists ( $\mathrm{HJJ}$ and $\mathrm{JHK}$ ) to confirm the diagnosis of bronchiectasis. In this study, long-term bronchodilator use was defined as administration of bronchodilator therapy for longer than 3 months. Responders were defined as those whose $\mathrm{FEV}_{1}$ values improved at least $12 \%$ and $200 \mathrm{~mL}$ from baseline $\mathrm{FEV}_{1}$ following 3-12 months of bronchodilator therapy. Patients who received long-term bronchodilator but did not meet these benchmarks were defined as poor responders.

Bronchodilators included inhaled long-acting $\beta_{2}$-agonists (LABAs) and inhaled long-acting muscarinic antagonist (LAMAs). Inhaled corticosteroids (ICS) exert an antiinflammatory response rather than bronchodilation, but have beneficial effects on lung-function improvement; ${ }^{24}$ therefore, this category was counted as one of the inhalers.

\section{Statistical analysis}

Data are presented as medians and interquartile ranges (IQRs; first to third) for continuous variables and as numbers 
and percentages for categorical variables. Data were compared using the Mann-Whitney $U$-test for continuous variables and Pearson's $\chi^{2}$ test or Fisher's exact test for categorical variables. To determine whether positive BDR at baseline was an independent factor for being a responder and to appreciate the influence of demographic, clinical, and treatment variables, a series of multiple logistic regression analyses were performed on variables with $P<0.2$ based on univariate results or clinically important: model 1 contained the demographic variables age (continuous), sex, and body mass index (BMI) (continuous); model 2 additionally included pulmonary-related variables, which are generally considered important in pulmonary diseases (smoking history [non- vs ex- or current smokers] and prebronchodilator $\mathrm{FEV}_{1}<50 \%$ predicted); and finally model 3 additionally included the treatment variable and number of inhalers, as well as all of the aforementioned variables. The incremental values of each addition of variables in the three models were evaluated via $\chi^{2}$ test. Next, we considered the stepwise selection of variables in a multiple logistic model to obtain a parsimonious prediction model containing only the relevant variables based on clinical and statistical significance. We used the HosmerLemeshow test to verify the goodness of fit for each model. All statistical tests were performed using SPSS version 22.0 (IBM, Armonk, NY, USA).

\section{Results}

\section{Clinical characteristics of participants}

The baseline characteristics of the 166 patients with bronchiectasis are shown in Table 1. Participants comprised 113 men (68.1\%) and 53 women (31.9\%) with a median age of 64 years (IQR 56-70 years). The median BMI was $22.8 \mathrm{~kg} / \mathrm{m}^{2}$ (IQR $20.7-25.4 \mathrm{~kg} / \mathrm{m}^{2}$ ), and 93 patients $(57.4 \%)$ were current or ex-smokers. A total of 74 patients (44.6\%) had a history of pulmonary tuberculosis, and common coexisting pulmonary diseases included nontuberculous mycobacterial lung disease $(n=13,7.8 \%)$ and chronic pulmonary aspergillosis $(n=5,3 \%)$. The most common extrapulmonary comorbidity was hypertension $(n=51,30.7 \%)$, followed by malignant disease $(n=23,13.9 \%)$, diabetes mellitus $(n=21$, $12.7 \%)$, chronic kidney disease $(n=7,4.2 \%)$, and cerebrovascular disease $(\mathrm{n}=7,4.2 \%)$. The median $\mathrm{FEV}_{1} / \mathrm{FVC}, \mathrm{FVC}$, and $\mathrm{FEV}_{1}$ were $53.7 \%, 2.8 \mathrm{~L}$ (70.5\% predicted), and $1.4 \mathrm{~L}$ (50\% predicted), respectively. Positive BDR at baseline was observed in 42 patients $(25.3 \%)$.

Among the 166 patients, there were 57 responders (34.3\%). Compared to poor responders, responders to treatment were more likely to be male $(78.9 \%$ [45 of 57] vs $62.4 \%$ [68 of 109], $P=0.03)$, current or ex-smokers $(69.6 \%$ [39 of 56] vs 50.9\% [54 of 106], $P=0.022)$ and have lower median $\mathrm{FEV}_{1} / \mathrm{FVC}$ (50.5\% [IQR 43.5\%-58\%] vs 55\% [IQR

Table I Comparison of clinical characteristics between poor responders and responders

\begin{tabular}{|c|c|c|c|c|}
\hline Characteristics & $\begin{array}{l}\text { Total } \\
(n=166)\end{array}$ & $\begin{array}{l}\text { Poor responders } \\
(n=109)\end{array}$ & $\begin{array}{l}\text { Responders } \\
(n=57)\end{array}$ & $P$-value \\
\hline Age, years & $64(56-70)$ & $62(54-70)$ & $64(59-70)$ & 0.202 \\
\hline Sex, male & II $3(68.1)$ & $68(62.4)$ & $45(78.9)$ & 0.03 \\
\hline Current smoker or ex-smoker & $93 / 162(57.4)$ & $54 / 106(50.9)$ & $39 / 56(69.6)$ & 0.022 \\
\hline Body mass index, $\mathrm{kg} / \mathrm{m}^{2}$ & $22.8(20.7-25.4)$ & $22.7(20.5-25.2)$ & $23.6(21.3-25.7)$ & 0.24 \\
\hline Body mass index $\geq 25 \mathrm{~kg} / \mathrm{m}^{2}$ & $51(30.7)$ & $30(27.5)$ & $21(36.8)$ & 0.217 \\
\hline Previous pulmonary tuberculosis & $74(44.6)$ & $5 \mathrm{I}(46.8)$ & $23(40.4)$ & 0.428 \\
\hline \multicolumn{5}{|l|}{ Coexisting pulmonary comorbidities } \\
\hline Bronchial asthma & $28(16.9)$ & $16(14.7)$ & $12(2 \mid .1)$ & 0.298 \\
\hline NTM lung disease & $13(7.8)$ & II (10.I) & $2(3.5)$ & 0.222 \\
\hline Chronic aspergillosis & $5(3)$ & $2(1.8)$ & $3(5.3)$ & 0.34 \\
\hline \multicolumn{5}{|l|}{ Extrapulmonary comorbidities } \\
\hline Hypertension & $5 \mathrm{I}(30.7)$ & $33(30.3)$ & $18(31.6)$ & 0.863 \\
\hline Malignant disease & $23(13.9)$ & $13(11.9)$ & $10(17.5)$ & 0.32 \\
\hline Diabetes mellitus & $21(12.7)$ & $14(12.8)$ & $7(12.3)$ & 0.917 \\
\hline Chronic kidney disease & $7(4.2)$ & $4(3.7)$ & $3(5.3)$ & 0.692 \\
\hline Cerebrovascular disease & $7(4.2)$ & $3(2.8)$ & $4(7)$ & 0.234 \\
\hline \multicolumn{5}{|l|}{ Baseline pulmonary function test } \\
\hline FVC, L & $2.8(2.1-3.3)$ & $2.6(2.1-3.4)$ & $2.9(2.3-3.2)$ & 0.526 \\
\hline FVC, \% predicted & $70.5(60.0-80.0)$ & $73.0(60.5-80.5)$ & $69.0(60.0-77.5)$ & 0.276 \\
\hline $\mathrm{FEV}_{1}, \mathrm{~L}$ & $1.4(1.1-1.8)$ & $\mathrm{I} .5(1.1-1.9)$ & $\mathrm{I} .4(\mathrm{I} . \mathrm{I}-\mathrm{I} .7)$ & 0.288 \\
\hline $\mathrm{FEV}_{1}, \%$ predicted & $50.0(39.0-61.0)$ & $51.0(39.5-63.0)$ & $46.0(38.0-55.5)$ & 0.065 \\
\hline $\mathrm{FEV}_{1} / \mathrm{FVC}, \%$ & $53.7(45.6-60.9)$ & $55(47-62.4)$ & $50.5(43.5-58)$ & 0.011 \\
\hline Positive bronchodilator response & $42(25.3)$ & $20(18.3)$ & $22(38.6)$ & 0.004 \\
\hline
\end{tabular}

Note: Data presented as $\mathrm{n}(\%)$ or medians and interquartile ranges.

Abbreviations: NTM, nontuberculous mycobacteria; FVC, forced vital capacity; FEV , forced expiratory volume in I second. 
47\%-62.4\% ], $P=0.011)$ and positive BDR at baseline $(38.6 \%$ [22 of 57] vs $18.3 \%$ [20 of 109], $P=0.004)$. There were no significant differences with respect to age, BMI, previous history of pulmonary tuberculosis, coexisting pulmonary or extrapulmonary comorbidities, or baseline pulmonary function tests, including FVC (percentage predicted, liters) and $\mathrm{FEV}_{1}$ (percentage predicted, liters) between the responders and poor responders.

\section{Comparison of CT findings and effect of inhaler therapy between responders and poor responders}

As shown in Table 2, the median number of involved lobes was three (IQR 2-5). Between responders and poor responders, there were no significant differences in the number of involved lobes or the locations of the involved lobes. A median of two inhalers (IQR 1-2) were used, and there were no significant differences in the number of inhalers used between the responders and poor responders. There were no significant differences in ICS use, LABA \pm ICS, or LAMA \pm ICS between responders and poor responders. However, LABA/ LAMA \pm ICS was more frequently used by responders than poor responders $(31.6 \%$ vs $16.5 \%, P=0.025)$.

\section{Association between positive BDR at baseline and being a responder following bronchodilator therapy}

The increase in $\mathrm{FEV}_{1}$ was more significant in patients with positive BDR at baseline compared to those without positive BDR at baseline (Figure 2; median $210 \mathrm{~mL}$
[IQR 130-430 mL] vs $130 \mathrm{~mL}$ [IQR -10 to $250 \mathrm{~mL}$ ], $P=0.001)$. In addition, patients with positive BDR at baseline were more likely to be responders to long-term bronchodilator therapy compared to those without positive BDR at baseline (Figure $3 ; 52.4 \%$ vs $28.2 \%, P=0.004$ ). However, the increase in $\mathrm{FEV}_{1}$ following bronchodilator therapy was statistically significant in patients without positive BDR at baseline (130 mL [IQR -10 to $250 \mathrm{~mL}$ ], $P<0.001$ ), as well as in those with positive BDR at baseline $(210 \mathrm{~mL}$ [IQR 130-430 mL], $P<0.001$ ) (Figure 4).

The three sequential models were compared for their incremental importance to predicting responsiveness to bronchodilator therapy. Compared to using only demographic variables (age, sex, and BMI) in model 1, model 2, which included pulmonary-related variables, including $\mathrm{FEV}_{1}$ $<50 \%$ predicted and smoking history, was marginally better $\left(\chi^{2}=0.47, P=0.79\right)$, while model 3 , including inhalers in addition to all previous variables, was significantly better in predicting the probability of responders $\left(\chi^{2}=6.03, P=0.049\right)$. As shown in Table 3, positive BDR at baseline remained consistently a significant predictive factor for being a responder to long-term bronchodilator therapy, with the exception of model 3, due to multiple insignificant variables making the model unstable.

We then considered risk-factor modeling to predict responsiveness by removing irrelevant variables, and found that positive BDR at baseline was 2.3 times more (confidence interval 1.067-4.951, $P=0.034$ ) significantly and independently associated with being a responder to long-term bronchodilator therapy than being a poor responder, in addition to the

Table 2 Comparison of CT findings and inhaler therapy between poor responders and responders

\begin{tabular}{|c|c|c|c|c|}
\hline & $\begin{array}{l}\text { Total } \\
(n=166)\end{array}$ & $\begin{array}{l}\text { Poor responders } \\
(n=109)\end{array}$ & $\begin{array}{l}\text { Responders } \\
(n=57)\end{array}$ & $P$-value \\
\hline \multicolumn{5}{|l|}{$C T$ findings } \\
\hline Number of involved lobes & $3(2-5)$ & $3(2-5)$ & $4(2-5)$ & 0.898 \\
\hline \multicolumn{5}{|l|}{ Involved lobe } \\
\hline Right upper lobe & $98(59)$ & $66(60.6)$ & $32(56.1)$ & 0.583 \\
\hline Right middle lobe & $104(62.7)$ & $67(61.5)$ & $37(64.9)$ & 0.663 \\
\hline Right lower lobe & $109(65.7)$ & $7 I(65.1)$ & $38(66.7)$ & 0.844 \\
\hline Left upper lobe & II8 (7I.I) & $77(70.6)$ & $4 I$ (7I.9) & 0.862 \\
\hline Left lower lobe & $128(77.1)$ & $87(79.8)$ & $4 \mid(7 \mid .9)$ & 0.251 \\
\hline \multicolumn{5}{|l|}{ Inhaler therapy } \\
\hline Number of inhalers & $2(I-2)$ & $2(I-2)$ & $2(I-3)$ & 0.076 \\
\hline Any ICS & $88(53)$ & $54(49.5)$ & 34 (59.6) & 0.215 \\
\hline LABA + LAMA $\pm I C S$ & $36(2 \mid .7)$ & $18(16.5)$ & $18(3 \mid .6)$ & 0.025 \\
\hline $\mathrm{LABA} \pm \mathrm{ICS}$ & $64(38.6)$ & $46(42.2)$ & $18(31.6)$ & 0.182 \\
\hline LAMA \pm ICS & 66 (39.8) & $45(4 I .3)$ & $21(36.8)$ & 0.579 \\
\hline
\end{tabular}

Note: Data are presented as $\mathrm{n}(\%)$ or medians and interquartile ranges.

Abbreviations: CT, computed tomography; ICS, inhaled corticosteroid; LABA, long-acting $\beta_{2}$-agonist; LAMA, long-acting muscarinic antagonist. 


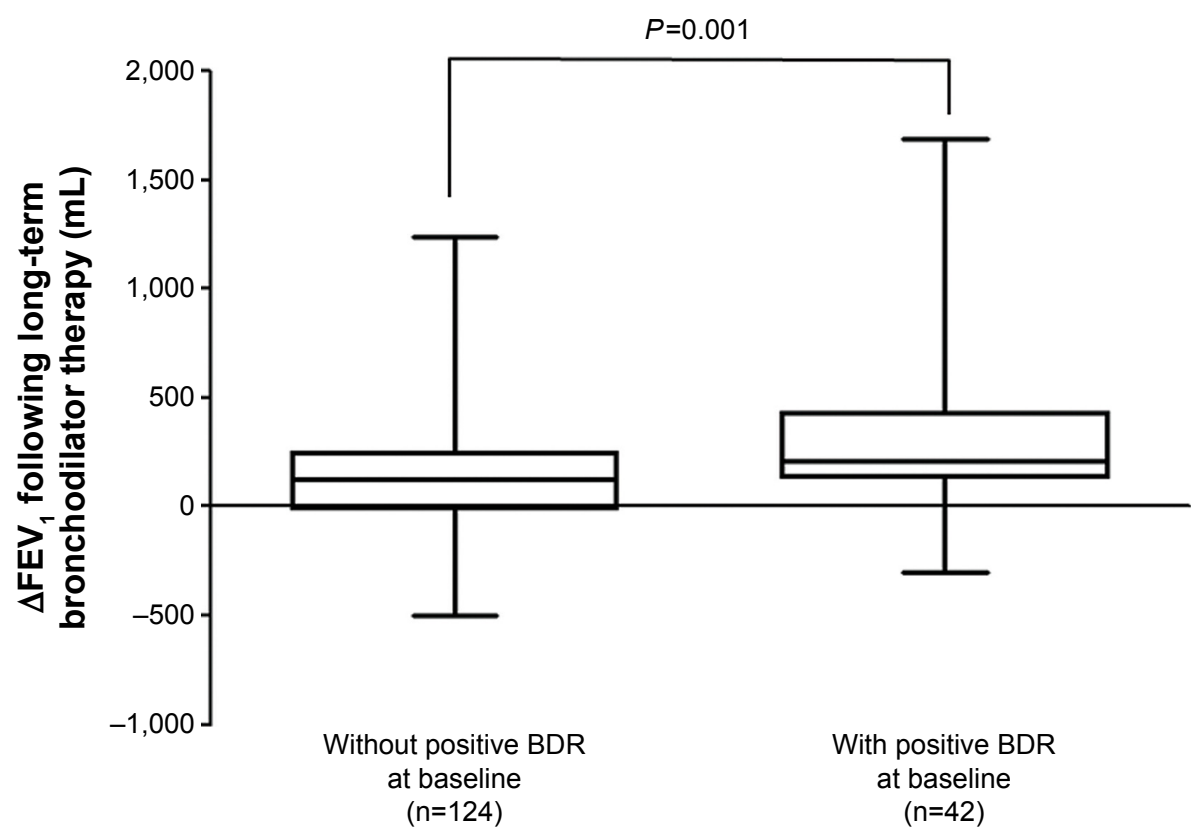

Figure 2 Comparison of change in FEV, between patients with and without positive BDR at baseline. Abbreviations: $\mathrm{FEV}$, forced expiratory volume in I second; BDR, bronchodilator response.

number of inhalers $(P=0.047)$. The goodness of fit of the model was confirmed by the Hosmer-Lemeshow test $(P>0.2)$.

\section{Discussion}

In the present study of bronchiectasis patients with airflow limitation, we found that approximately one-third of patients were responders to long-term bronchodilator therapy, and positive BDR at baseline was significantly associated with an increase in $\mathrm{FEV}_{1}$ following long-term bronchodilator therapy. However, the increase in $\mathrm{FEV}_{1}$ was evident not only in patients with positive BDR at baseline but also in those

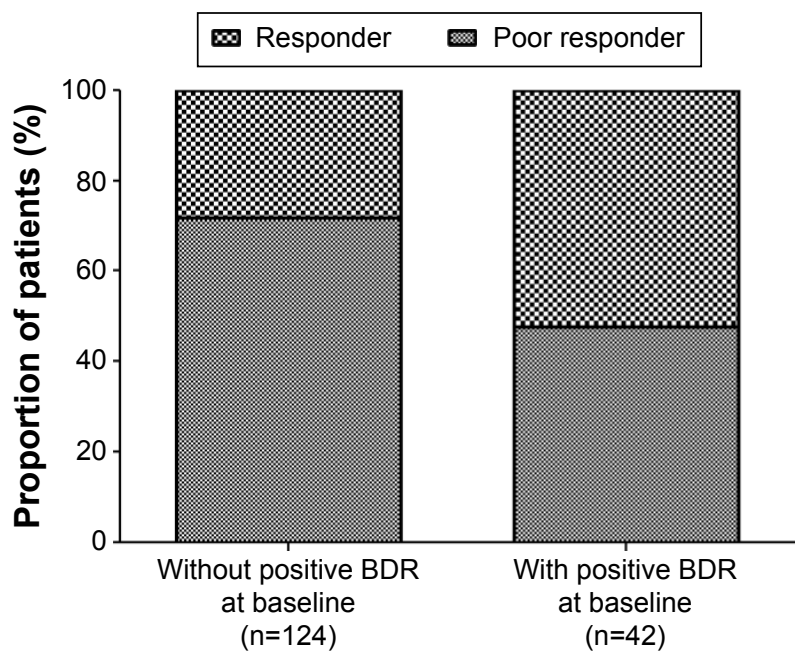

Figure 3 Relationship between presence of BDR at baseline and response to longterm bronchodilator therapy in bronchiectasis patients.

Abbreviation: BDR, bronchodilator response. without positive BDR at baseline. Therefore, our findings suggest that patients with bronchiectasis who demonstrate poor BDR at baseline can benefit from long-term bronchodilator therapy.

To the best of our knowledge, this is the first study to investigate the relationship between positive BDR at baseline and the long-term effects of bronchodilator therapy in patients with bronchiectasis. In the treatment of patients with bronchiectasis, bronchodilator use is recommended for patients with positive BDR at baseline. ${ }^{7}$ This recommendation is based on results from two previous studies that demonstrated significant BDR (greater than $15 \%$ improvement in $\mathrm{FEV}_{1}$ ) in a subset of patients with bronchiectasis after use of a short-acting bronchodilator. ${ }^{5,14}$ However, these studies evaluated BDR in fewer than 30 patients with bronchiectasis (one study included 24 patients and the second included 16 patients), and did not confirm the long-term effect of bronchodilator therapy based on immediate BDR. In a relatively larger number of patients, our study confirmed and extended the previous findings, showing that about $25 \%$ of bronchiectasis patients with airflow limitation had positive BDR at baseline, and the presence of positive BDR at baseline was independently associated with improvement in lung function following long-term bronchodilator therapy in patients with bronchiectasis and airflow limitation. These findings are consistent with results from studies on COPD patients. The predictive ability of airflow reversibility in a short-acting bronchodilator test 


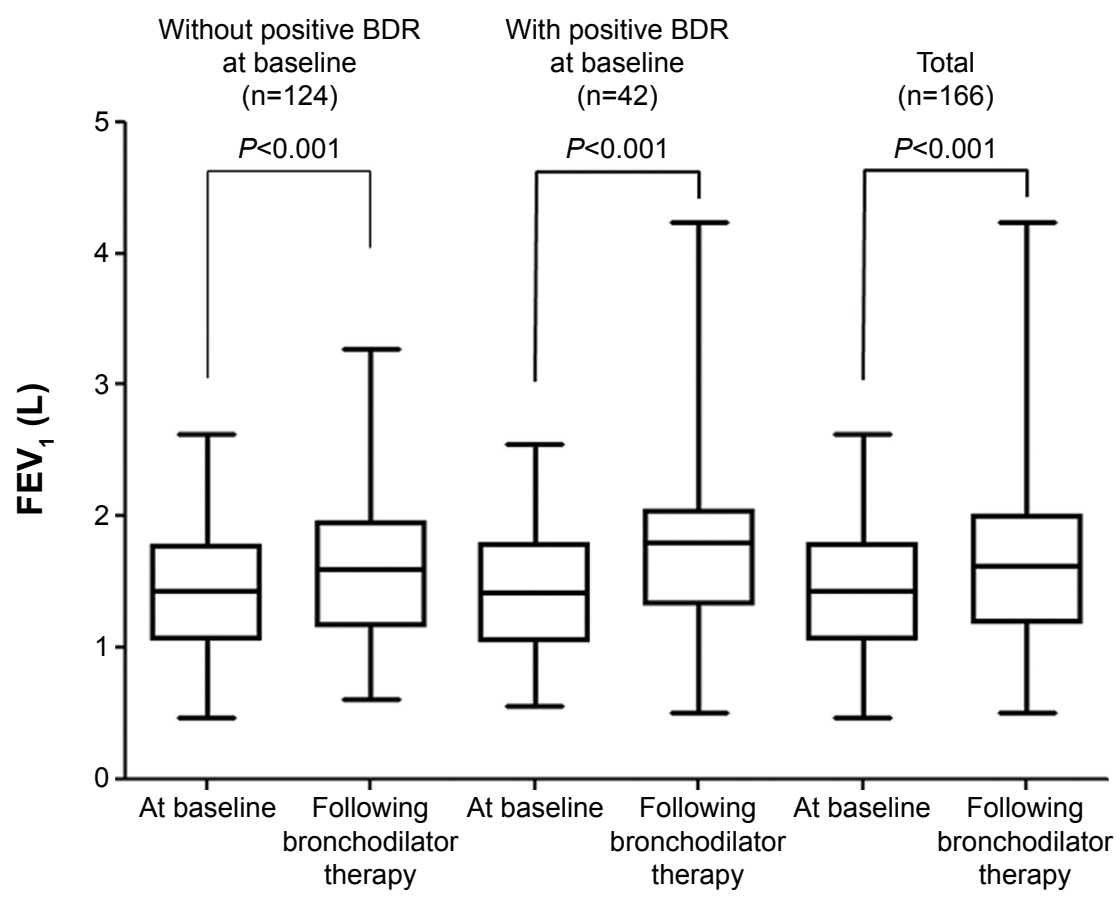

Figure 4 Comparison of $\mathrm{FEV}_{1}$ at baseline and following long-term (3-12 months) bronchodilator therapy. Abbreviation: $\mathrm{FEV}_{1}$, forced expiratory volume in I second; BDR, bronchodilator response.

on long-term improvements in lung function following bronchodilator therapy in patients with COPD has been widely studied. ${ }^{15,25,26} \mathrm{~A}$ randomized controlled trial showed that COPD patients with immediate BDR after the first dose of tiotropium showed a larger improvement in $\mathrm{FEV}_{1}$ following 1 year of tiotropium use compared to COPD patients without immediate BDR..$^{15}$ Other studies that evaluated the effects of salmeterol on COPD patients have also shown that patients with positive BDR at baseline had larger improvements in lung function at 12 weeks and 1 year following the use of salmeterol compared with those without positive BDR at baseline. ${ }^{25,26}$

Table 3 aORs of positive bronchodilator response at baseline for responders after at least 3 months of bronchodilator therapy

\begin{tabular}{llll}
\hline Model & aOR & $\mathbf{9 5 \%} \mathbf{C l}$ & $P$-value \\
\hline Model I & 2.559 & $1.188-5.513$ & 0.016 \\
Model 2 & 2.407 & $1.096-5.283$ & 0.029 \\
Model 3 & 1.984 & $0.871-4.520$ & 0.103 \\
Final model & 2.298 & $1.067-4.951$ & 0.034 \\
\hline
\end{tabular}

Notes: Model I was adjusted for age, sex, and BMI, model 2 was additionally adjusted for pulmonary-related variables (smoking history and baseline prebronchodilator $\mathrm{FEV},<50 \%$ predicted), and model 3 was additionally adjusted for number of inhalers and all of the aforementioned variables. The increment of additional variables had $P$-values of 0.79 for comparing model I vs model 2 and 0.062 for comparing model 2 vs model 3 . However, the $P$-value was 0.049 when comparing model I vs model 3 . The final model included only significant clinical or statistical variables, which were the number of inhalers and positive BDR at baseline.

Abbreviations: aOR, adjusted odds ratio; $\mathrm{Cl}$, confidence interval; $\mathrm{BMI}$, body mass index; $\mathrm{FEV}_{1}$, forced expiratory volume in I second; BDR, bronchodilator response.
However, special attention should be given to patients without positive BDR at baseline. We observed that patients without positive BDR at baseline also exhibited significant improvement in $\mathrm{FEV}_{1}$ following long-term bronchodilator therapy, although those with positive BDR at baseline had greater improvement in $\mathrm{FEV}_{1}$ than those without positive BDR at baseline. This pattern has also been recognized in COPD patients. Despite the positive correlation between short-term response to bronchodilator at baseline and improvement in lung function following long-term bronchodilator therapy, several studies of COPD patients have found that long-term bronchodilator therapy significantly improved lung function, dyspnea, and health status, irrespective of the presence or absence of positive BDR at baseline. ${ }^{15,25-29}$ These findings led to the current guidelines that do not recommend use of reversibility testing with short-acting bronchodilator use to predict long-term response to treatment. Therefore, our results suggest that long-term bronchodilator use needs to be extended to patients without positive BDR at baseline in patients with bronchiectasis and airflow limitation. However, a randomized clinical trial with a placebo group is needed to establish the efficacy of long-term bronchodilator use in patients with bronchiectasis.

The coexistence of bronchial asthma in bronchiectasis patients has been reported, ${ }^{30,31}$ and a recent study has shown that the existence of bronchial asthma is an independent risk 
factor for bronchiectasis exacerbations. ${ }^{30}$ Regarding lung function improvement following long-term bronchodilator therapy with ICS, our study showed that coexisting bronchial asthma was not associated with being a responder in patients with bronchiectasis. Our study included only bronchiectasis patients who had airflow limitation, which could have mitigated the effect of bronchodilator therapy with ICS on coexisting bronchial asthma patients with bronchiectasis. Further studies are necessary to investigate the effect of long-term bronchodilator therapy with ICS on the rate of exacerbations in patients with both bronchial asthma and bronchiectasis.

\section{Limitations}

This study has several limitations. First, it was retrospectively performed in a single tertiary hospital. Second, patients who had not undergone spirometry after 3-12 months following bronchodilator therapy were excluded, which may have led to selection bias. Third, the rate of exacerbations, changes in symptoms, and health-related quality of life following longterm use of bronchodilators were not evaluated, which could represent additional long-term benefits to maintenance therapy with bronchodilators. Fourth, the duration of bronchodilator use was different in each patient. However, the duration of 3-12 months was long enough to observe improvements in $\mathrm{FEV}_{1}$, and there was no significant difference in the median duration of bronchodilator use between responders and poor responders. Finally, although we showed that bronchodilators are useful in improving lung function, the optimal inhalers for bronchiectasis patients could not be evaluated from our study. Therefore, further studies are necessary to compare the effectiveness of each type of bronchodilator in patients with bronchiectasis.

\section{Conclusion}

In summary, we conclude that positive BDR at baseline was an independent predictive factor for improvement in lung function after long-term bronchodilator therapy in patients with bronchiectasis and airflow limitation. We further suggest that clinicians should consider long-term bronchodilator therapy for patients with poor BDR at baseline, as it can exhibit beneficial response.

\section{Disclosure}

The authors report no conflicts of interest in this work.

\section{References}

1. Amalakuhan B, Maselli DJ, Martinez-Garcia MA. Update in Bronchiectasis 2014. Am J Respir Crit Care Med. 2015;192(10):1155-1161.
2. Cole PJ. Inflammation: a two-edged sword - the model of bronchiectasis. Eur J Respir Dis Suppl. 1986;147:6-15.

3. Roberts HR, Wells AU, Milne DG, et al. Airflow obstruction in bronchiectasis: correlation between computed tomography features and pulmonary function tests. Thorax. 2000;55(3):198-204.

4. Ho PL, Chan KN, Ip MS, et al. The effect of Pseudomonas aeruginosa infection on clinical parameters in steady-state bronchiectasis. Chest. 1998;114(6):1594-1598.

5. Nogrady SG, Evans WV, Davies BH. Reversibility of airways obstruction in bronchiectasis. Thorax. 1978;33(5):635-637.

6. Pang J, Chan HS, Sung JY. Prevalence of asthma, atopy, and bronchial hyperreactivity in bronchiectasis: a controlled study. Thorax. 1989;44(11):948-951.

7. Pasteur MC, Bilton D, Hill AT. British Thoracic Society guideline for non-CF bronchiectasis. Thorax. 2010;65 Suppl 1:i1-i58.

8. McShane PJ, Naureckas ET, Tino G, Strek ME. Non-cystic fibrosis bronchiectasis. Am J Respir Crit Care Med. 2013;188(6):647-656.

9. Martínez-García MA, Perpiñá-Tordera M, Román-Sánchez P, Soler-Cataluña JJ. Inhaled steroids improve quality of life in patients with steady-state bronchiectasis. Respir Med. 2006;100(9): $1623-1632$.

10. Tsang KW, Tan KC, Ho PL, et al. Inhaled fluticasone in bronchiectasis: a 12 month study. Thorax. 2005;60(3):239-243.

11. Wong C, Jayaram L, Karalus N, et al. Azithromycin for prevention of exacerbations in non-cystic fibrosis bronchiectasis (EMBRACE): a randomised, double-blind, placebo-controlled trial. Lancet. 2012; 380(9842):660-667.

12. Altenburg J, de Graaff CS, Stienstra Y, et al. Effect of azithromycin maintenance treatment on infectious exacerbations among patients with non-cystic fibrosis bronchiectasis: the BAT randomized controlled trial. JAMA. 2013;309(12):1251-1259.

13. Serisier DJ, Martin ML, McGuckin MA, et al. Effect of long-term, lowdose erythromycin on pulmonary exacerbations among patients with non-cystic fibrosis bronchiectasis: the BLESS randomized controlled trial. JAMA. 2013;309(12):1260-1267.

14. Hassan JA, Saadiah S, Roslan H, Zainudin BM. Bronchodilator response to inhaled beta-2 agonist and anticholinergic drugs in patients with bronchiectasis. Respirology. 1999;4(4):423-426.

15. Tashkin D, Kesten S. Long-term treatment benefits with tiotropium in COPD patients with and without short-term bronchodilator responses. Chest. 2003;123(5):1441-1449.

16. Sheikh A, Nolan D, Greenstone M. Long-acting $\beta 2$-agonists for bronchiectasis. Cochrane Database Syst Rev. 2001;(4):CD002155.

17. Franco F, Sheikh A, Greenstone M. Short acting $\beta 2$ agonists for bronchiectasis. Cochrane Database Syst Rev. 2003;(3):CD003572.

18. Guan WJ, Gao YH, Xu G, et al. Bronchodilator response in adults with bronchiectasis: correlation with clinical parameters and prognostic implications. J Thorac Dis. 2016;8(1):14-23.

19. Miller MR, Hankinson J, Brusasco V, et al. Standardisation of spirometry. Eur Respir J. 2005;26(2):319-338.

20. Choi JK, Paek DM, Lee JO. Normal predictive values of spirometry in Korean population. Tuberc Respir Dis. 2005;58(3):230-242.

21. Pellegrino R, Viegi G, Brusasco V, et al. Interpretative strategies for lung function tests. Eur Respir J. 2005;26(5):948-968.

22. Dodd JD, Lavelle LP, Fabre A, Brady D. Imaging in cystic fibrosis and non-cystic fibrosis bronchiectasis. Semin Respir Crit Care Med. 2015; 36(2):194-206.

23. Hansell DM, Bankier AA, MacMahon H, McLoud TC, Müller NL, Remy J. Fleischner Society: glossary of terms for thoracic imaging. Radiology. 2008;246(3):697-722.

24. Calverley PM, Anderson JA, Celli B, et al. Salmeterol and fluticasone propionate and survival in chronic obstructive pulmonary disease. N Engl J Med. 2007;356(8):775-789.

25. Rennard SI, Anderson W, ZuWallack R, et al. Use of a long-acting inhaled $\beta 2$-adrenergic agonist, salmeterol xinafoate, in patients with chronic obstructive pulmonary disease. Am J Respir Crit Care Med. 2001;163(5):1087-1092. 
26. ZuWallack RL, Mahler DA, Reilly D, et al. Salmeterol plus theophylline combination therapy in the treatment of COPD. Chest. 2001;119(6): 1661-1670.

27. Bleecker ER, Emmett A, Crater G, Knobil K, Kalberg C. Lung function and symptom improvement with fluticasone propionate/salmeterol and ipratropium bromide/albuterol in COPD: response by beta-agonist reversibility. Pulm Pharmacol Ther. 2008;21(4):682-688.

28. Mahler DA, Donohue JF, Barbee RA, et al. Efficacy of salmeterol xinafoate in the treatment of COPD. Chest. 1999;115(4):957-965.
29. Tashkin DP, Celli B, Decramer M, et al. Bronchodilator responsiveness in patients with COPD. Eur Respir J. 2008;31(4):742-750.

30. Mao B, Yang JW, Lu HW, Xu JF. Asthma and bronchiectasis exacerbation. Eur Respir J. 2016;47(6):1680-1686.

31. Saynajakangas O, Keistinen T, Tuuponen T, Kivela SL. Links between hospital diagnoses of bronchiectasis and asthma. Allergy. 1997;52(11): $1120-1122$.

\section{Publish your work in this journal}

The International Journal of COPD is an international, peer-reviewed journal of therapeutics and pharmacology focusing on concise rapid reporting of clinical studies and reviews in COPD. Special focus is given to the pathophysiological processes underlying the disease, intervention programs, patient focused education, and self management protocols.

\section{Dovepress}

This journal is indexed on PubMed Central, MedLine and CAS. The manuscript management system is completely online and includes a very quick and fair peer-review system, which is all easy to use. Visit http://www.dovepress.com/testimonials.php to read real quotes from published authors. 